\title{
An Epistemology for Practical Knowledge
}

\section{Lucy Campbell}

Faculty of Philosophy, University of Oxford, Oxford, UK

lucy.campbell@philosophy.ox.ac.uk; lucypcampbell@yahoo.com 


\section{An Epistemology for Practical Knowledge}

Anscombe thought that practical knowledge - a person's knowledge of what she is intentionally doing - displays formal differences to ordinary empirical, or 'speculative', knowledge. I suggest these differences rest on the fact that practical knowledge involves intention analogously to how speculative knowledge involves belief. But this claim conflicts with the standard conception of knowledge, according to which knowledge is an inherently belief-involving phenomenon. Building on John Hyman's $(1999,2015)$ account of knowledge as the ability to use a fact as a reason, I develop an alternative, two-tier, epistemology which allows that knowledge might really come in a belief-involving and an intention-involving form.

Keywords: practical knowledge, speculative knowledge, self-knowledge, Intention, Anscombe, knowledge as an ability, two-tier epistemology.

\section{Introduction ${ }^{1}$}

Anscombe characterised practical knowledge - a person's knowledge that she is $\varphi$-ing, when she is doing so intentionally ${ }^{2}$ - as knowledge 'in intention' (57). ${ }^{3}$

On my interpretation, Anscombe does not mean by this merely that practical knowledge has as its object intentional action. She means, in addition, and much more radically, that practical knowledge involves an intention to $\varphi$ analogously to how ordinary empirical knowledge of worldly facts - what she calls 'speculative' knowledge - involves a belief that $p$. Anscombe's idea is that practical knowledge is knowledge 'in intention' analogously to how speculative knowledge might be said to be knowledge 'in belief'.

According to a familiar conception of knowledge which I'll call the 'Belief Account of knowledge' (or just 'the Belief Account'), whenever someone knows that $p$, she does so by or in (truly) believing that $p$ : the Belief Account holds that all knowledge is knowledge 'in belief' ${ }^{4}$ Against this background, the only way that practical knowledge could be knowledge 'in

\footnotetext{
${ }^{1}$ For discussion of various issues in this paper, and/or for comments on previous incarnations of it, I am very grateful to Maria Alvarez, Michael Brent, Casey Doyle, Anil Gomes, Alexander Greenberg, Josh HabgoodCoote, Jane Heal, John Hyman, Stephen Mulhall, Kegan Shaw, Lukas Skiba, Silvan Wittwer, and the audiences of the Early Career Mind Network meeting in Warwick in April 2016, and of a workshop as part of the Knowledge-First Philosophy of Mind project in Oxford in May 2017. Especial thanks are due to two anonymous referees for this journal, who provided invaluable feedback on an earlier draft.

${ }^{2}$ We also often have practical knowledge of what we will (intentionally) do, and of why we are acting. I leave these aspects of practical knowledge to one side to simplify my discussion.

${ }^{3}$ Unless otherwise indicated, page numbers refer to Anscombe's (1957) Intention (the First Harvard University Press paperback edition, 2000).

${ }^{4}$ Proponents of the Belief Account disagree over whether knowledge can be analysed as a certain kind of true belief. For the canonical contemporary expression of the view that it cannot, see Williamson $(2000,47)$.
} 
intention' would be if intentions were themselves a kind of belief. Such an approach has been developed by David Velleman $(1989,2000)$ and Kieran Setiya $(2008,2009)$.

I think that there are deep problems with identifying intentions as a kind of belief. I will not argue for this, however (although see Langton [2004]; Bratman [2009]; Holton [2009, Ch. 1]), for the aim of this paper is to consider the much more radical idea that practical knowledge is knowledge 'in intention' rather than (and not, as Velleman and Setiya would have it, as well as) knowledge 'in belief'. It is this that I take to be Anscombe's view, and it is radical precisely because it is incompatible with the Belief Account of knowledge. For the Belief Account has the status of a philosophical orthodoxy.

Taking Anscombe's account of practical knowledge seriously means rejecting the Belief Account and turning to a different general epistemology. John Hyman has defended the idea that propositional knowledge is not a form of belief, but a form of ability: it is the ability to use a fact as a reason (Hyman 1999, 2015). I will argue that unlike the Belief Account, an Ability Account can accommodate both a belief-involving and a - distinct - intention-involving form of knowledge. Abilities are often underwritten by states, and I will suggest that it is plausible to think of the knowledge-ability (the ability to use a fact as a reason) as underwritten in cases of speculative knowledge by belief, but in cases of practical knowledge, by intention.

The result is a two-tier epistemology comprising an account of the genus knowledge, understood following Hyman as a kind of rational ability, and an account of how its species (speculative knowledge, practical knowledge) are differentiated, which is given by distinguishing the different mental states which underwrite the knowledge-ability (belief, intention).

In $§ 1$ I explain why we should understand Anscombe's distinction between practical and speculative knowledge as a distinction between an intention-involving and a beliefinvolving form of knowledge. In §2 I introduce Hyman's Ability Account of knowledge, and locate Anscombe's distinction within it, developing and motivating the two-tier epistemology outlined above. I conclude in $\S 3$ by explaining how Hyman's and Anscombe's epistemologies mutually benefit from my suggested merger, and by suggesting that my two-tier account might also provide a framework for understanding psychological self-knowledge, which I suggest is plausibly neither 'practical' nor 'speculative' in Anscombe's senses.

\section{Anscombe on 'practical' and 'speculative' knowledge}

This section outlines how I think we should understand Anscombe's distinction between practical and speculative knowledge. Whilst I think that the account I outline in this section can 
be defended as a reading of Anscombe by close and careful attention to the text of Intention, providing this goes beyond the scope of my discussion. ${ }^{5}$

Positively, I will describe two formal features which Anscombe claims characterise practical knowledge, in contradistinction to speculative knowledge (§1.1), explain how thinking of practical knowledge as having these features has significant explanatory power (§1.2), and then argue that the best way of understanding why practical and speculative knowledge should differ formally in the ways described in $\S 1.1$, is to see them as involving different kinds of mental state: intention and belief respectively $(§ 1.3)$.

\section{a. Aquinas' and Theophrastus' Features}

Anscombe borrows from Aquinas the idea that,

Practical knowledge is 'the cause of what it understands', unlike speculative knowledge, which 'is derived from the objects known'. (87)

Call being the cause of what it understands (rather than being derived from the objects known) 'Aquinas' Feature'. ${ }^{6}$

Consider a piece of speculative knowledge; my knowledge that the pangolin is endangered. It is (inter alia) because the pangolin is endangered that I know that it is - my knowledge is in a certain sense a response to the fact which is its object. In this sense, my knowledge that the pangolin is endangered is 'derived from the objects known'. This is a formal feature of all speculative knowledge, according to Anscombe.

It is standard - these days as when Intention was written - to think that all knowledge is 'derived from the objects known'. But Anscombe thinks this is a mistake (57). Practical knowledge, she thinks, works differently. Take my practical knowledge that I'm (intentionally) drinking my coffee. Here it seems that it is because I know that I am intentionally drinking my coffee that I am indeed doing so: were I drinking my coffee unawares, I would not be doing so intentionally. (Although of course I may still be doing so, if e.g. I think I'm drinking yours instead.) Here, the object of my knowledge - the fact that I am intentionally drinking my coffee - seems to be dependent on my knowing it. In this sense, my knowledge that I am drinking my

\footnotetext{
${ }^{5}$ For some excellent alternative discussions of Anscombe on practical knowledge, see Moran (2004), Rödl (2007), Haddock (2011), Thompson (2011), and, for readers also particularly interested in Anscombe interpretation, Teichmann (2008), and Wiseman (2016).

${ }^{6}$ It is less than clear whether Anscombe herself interprets Aquinas correctly, or indeed whether she sees herself as agreeing with Aquinas' view in any strong sense, rather than merely borrowing from him a handy slogan. 'Aquinas' Feature' is nonetheless a handy label for this feature of practical knowledge. Thanks to John Hyman for pressing me to clarify this issue.
} 
coffee is 'the cause of what it understands'. ${ }^{7}$ Anscombe suggests that all practical knowledge shares this feature.

A second formal feature Anscombe thinks characterises practical (and not speculative) knowledge, is introduced in the following passage:

In some cases, the facts are, so to speak, impugned for not being in accordance with the words [or judgment], rather than vice versa. (5)

In such cases,

the mistake is not one of [words or] judgment, but of performance. That is, we do not say: What you said [judged] was a mistake, because it was supposed to describe what you did and did not describe it, but: What you did was a mistake, because it was not in accordance with what you said [judged]. (57)

Because knowledge is factive, it will always be undermined by a mismatch between judgment and fact: such a mismatch will amount to a mistake, failure, error (etc.) for someone aiming at knowledge. We are used to thinking of a fact-judgment mismatch as embodying a mistaken judgment: if Jenni thinks the pangolin is prospering, she thinks wrongly, because the pangolin is endangered.

The idea in the passages above is that this is not the only way in which a fact-judgment mismatch might embody a knowledge-undermining mistake. A mismatch between one's judgment and the facts might, instead, embody a mistake in what one did. It will involve this, thinks Anscombe, just when one was attempting to do something intentionally, and so, just when the knowledge one was aiming at is practical knowledge. If I think I'm drinking my coffee, but am in fact drinking yours, the problem is with what I'm doing, and what I'm doing is wrong precisely because it mismatches with what I took myself to be doing, viz. drinking my coffee. There is a knowledge-undermining fact-judgment mismatch here, but the mistake is with my performance, not with my judgment.

This shows up in the fact that when you tell me that it's your coffee I'm drinking, and not mine, I will (typically) not simply change my mind about whose coffee I am drinking and carry on, but will put down your cup and pick up my own (cf. 56-57). What I am doing in such a case is adjusting my behaviour to match up to the persisting judgment, 'I'm drinking my

\footnotetext{
${ }^{7}$ Anscombe is clear (87-88) here that by 'cause' she means formal and not efficient cause (contra e.g. Velleman $[1989,102$, n. 24]). It is common to think that practical knowledge cannot be the formal cause of what it understands because it is possible to do something intentionally without being confident that one is succeeding, and so without knowing that one is doing it (e.g. Davidson [2001, 50]). I don't think these considerations show as much as they are usually taken to. It would go beyond the scope to argue this, but see e.g. Thompson (2011).
} 
coffee'. It is because I take drinking my coffee to be what I'm up to that it makes sense for me to put your cup down, and pick up my own, thus getting my performance to match up to my judgement about what I am doing. ${ }^{8}$

Anscombe attributes the distinction between the above two ways in which a factjudgment mismatch can be normatively assessed to Theophrastus $(5,82)$. So I will refer to this second formal characteristic of practical knowledge - being undermined by a mistaken performance rather than (as in speculative knowledge) by a mistaken judgment - as 'Theophrastus' Feature'.

\section{b. Why Aquinas' and Theophrastus' Features?}

Anscombe's characterisation of practical knowledge as displaying Aquinas' and Theophrastus' Features might seem odd or obscure. It has certainly proved controversial, ${ }^{9}$ which should be no surprise, for Anscombe herself accepts that her suggestion is at odds with the orthodox epistemological assumptions of 'modern philosophy'. Indeed, she considers such assumptions responsible for deep misunderstandings about practical knowledge (57).

Part of what requires understanding about practical knowledge is why it should be firstperson authoritative and apparently epistemically ungrounded in evidence or perception (why it should be a kind of 'non-observational' knowledge). Seeing practical knowledge as distinguished by Aquinas' and Theophrastus' Features has significant explanatory power in this context, as I will explain.

We can think of practical knowledge's first-person authority as an epistemic privilege enjoyed by an agent, in comparison to others, in relation to the fact that she is intentionally $\varphi$ ing. And just such a privilege would follow if practical knowledge displayed Aquinas' Feature: if the fact that I am intentionally drinking my coffee depends on my knowing that I am, then $m y$ epistemic relationship to this fact is clearly privileged compared to anyone else's.

One way of bringing out the fact that practical knowledge appears evidentially and perceptually ungrounded is to note that it seems out of place to ask someone who is intentionally $\varphi$-ing what her evidence is for thinking that she is, and that someone who knows that she is $\varphi$-ing only because she (e.g.) visually notices herself $\varphi$-ing, seems to be someone

\footnotetext{
${ }^{8}$ Note that Anscombe needn't deny that I also judge wrongly here. The important idea is that if there is a mistaken judgment in such a case, this does not undermine the agent's practical knowledge, which is instead undermined by a mistaken performance. Anscombe seemed to think that in a successful case, both practical and speculative knowledge will be present: ' $\ldots$ in any operation we can really speak of two knowledges - the account that one could give of what one was doing, without adverting to observation; and the account of exactly what is happening at a given moment (say) to the material one is working on. The one is practical, the other speculative' (88-89). This would mean that in an error case, both practical and speculative knowledge are undermined, the former by a mistaken performance, the latter by a mistaken judgment.

${ }^{9}$ For some characteristic rejections of various aspects of the idea, see (Velleman 1989; Setiya 2008; Paul 2009; Grünbaum 2009; Newstead 2006, 2009). I will briefly touch on the penultimate complaint in $§ 1.3$.
} 
who is precisely not $\varphi$-ing intentionally (cf. 14). Yet despite appearing to be epistemically ungrounded, we accept that people's judgments about what they are intentionally doing can and do constitute genuine knowledge.

The standard response to such observations is to try to describe 'hidden' epistemic grounds for practical knowledge, and explain away its ungroundedness as merely apparent (see e.g. Donnellan [1963], Velleman [1989], O’Brien [2003], Pickard [2004], Setiya [2008, 2009], Paul [2009]). But Anscombe's account enables us to save the commonsense appearances. Both Aquinas' and Theophrastus' features play a role here.

First, displaying Theophrastus' Feature would mean that practical knowledge does not need epistemic grounds. For - to speak metaphorically - the role of evidence, perception (etc.) is to guide one's judgment in the direction of the facts. And this will be necessary only for judgments which require such guidance. And whilst - for Anscombe - this is the case in speculative knowledge, in practical knowledge it is the performance's job to match up with the judgment. So whilst (e.g.) vision may help me get my performance in line with my judgment that I am drinking coffee, it is not here providing me with an epistemic ground for this judgment. It is not playing the same kind of role in my practical knowledge that I am drinking my coffee as it might play in my (speculative) knowledge that (e.g.) you are drinking your coffee $(50,82)$.

Second, Aquinas' Feature explains why practical knowledge could not be - specifically - perceptually grounded. For although we often can (e.g.) see what our limbs are doing, and the ways they affect our surroundings, perception can only take in facts which are there to be taken in independently of it. Perception is able to ground speculative knowledge, which is 'derived from the objects known', but it could not ground practical knowledge, understood as 'the cause of what it understands'.

Fully defending Anscombe's controversial characterisation of practical knowledge in terms of Aquinas' and Theophrastus' features is beyond the scope of my discussion, but I hope to have clarified a key motivation for the account: commonsense sees practical knowledge as differing to much ordinary empirical knowledge in being first-person authoritative and in seeming epistemically ungrounded. And knowledge with Aquinas' and Theophrastus' Features would display these very characteristics.

\section{c. Practical knowledge as knowledge 'in intention'}

So whilst controversial, Anscombe's account of practical knowledge as characterised by Aquinas' and Theophrastus' Features has significant explanatory power, and allows us to save the commonsense appearances when it comes to practical knowledge's first-person authority and epistemic ungroundedness. Now I want to explain why someone who agrees that we should 
see practical knowledge as characterised by Aquinas' and Theophrastus' Features ought to think of practical knowledge as involving intention analogously to how speculative knowledge involves belief.

I take it that the idea that knowledge in some sense involves belief is familiar, even if in need of clarification. I will provide a clarification in $\S 3.1$, but for now, we can draw on this familiar idea in understanding the more general idea of a bit of knowledge 'involving' a psychological state, and the suggestion I want to make that practical knowledge 'involves' intention rather than belief.

Consider first how thinking of practical knowledge as involving intention rather than belief explains why it displays Aquinas' Feature.

The fact that practical knowledge displays Aquinas' Feature means that the descriptions under which one is acting intentionally are determined by the contents of one's practical knowledge. ${ }^{10}$ And it is the contents of the intentions one is executing which determine the descriptions under which one is acting intentionally. ${ }^{11}$ I might be drinking my coffee intentionally, and in so doing also sloshing it out of the cup, but not doing this intentionally, because whilst in acting I am executing an intention to drink my coffee, I am not executing an intention to slosh it. If my practical knowledge involves my intentions, and my intentions determine the descriptions under which I am acting intentionally, it should be no surprise that the descriptions under which I am acting intentionally would be determined by the contents of my practical knowledge.

By contrast, thinking of practical knowledge as, like speculative knowledge, involving belief leaves Aquinas' Feature unexplained. For say I know both that I am drinking my coffee, and that I am sloshing it. If my knowledge that I am doing both of these things is equally beliefinvolving, then it remains to be explained why my knowledge that I am drinking my coffee is 'the cause of what it understands', whereas my knowledge that I am sloshing it out of the cup is 'derived from the objects known'. The point is not that it is impossible to provide this explanation whilst holding that both my (practical) knowledge that I am drinking my coffee and my (speculative) knowledge that I am sloshing it equally involve my beliefs. It is rather that, as described above, Aquinas' Feature simply falls out of an account of practical knowledge as involving intention rather than belief.

Let's turn to considering how thinking of practical knowledge as involving intention rather than belief explains why it should display Theophrastus' Feature.

\footnotetext{
${ }^{10}$ The idea that actions are intentional (only) under a description is standard, but for a defence of it see Anscombe (1957, 11-12; 1979).

${ }^{11}$ Michael Bratman has denied this, arguing that not all intentional $\varphi$-ings are executions of an intention to $\varphi$ (so that I may not intend to put my right foot forward, whilst walking, but as long as I do so in service of my intention to walk, I do so intentionally). I don't find Bratman's argument convincing, but explaining why would take us too far afield. For discussion, see Bratman (1984), Ezio (2009).
} 
In displaying Theophrastus' Feature, practical knowledge is undermined by a mistaken performance, where it is the agent's judgment which sets the standard against which a performance will count as successful, or mistaken.

Seeing practical knowledge as involving intention rather than belief explains this because of the kind of attitude intention is: intentions set standards on performance where beliefs, by contrast, have standards set for them by how things are with the facts. ${ }^{12}$ When I judge 'I am drinking my coffee', but am in fact drinking yours, my mistake is a mistake in performance precisely because drinking my coffee is what I intend to be doing. If we think of my judgment 'I am drinking my coffee' as an intention rather than a belief, it is easy to see how a fact-judgment mismatch could embody a mistake in performance and not in judgment.

This point also undermines a certain kind of criticism of Anscombe's characterisation of practical knowledge as displaying Theophrastus' feature, viz. that in knowing, a person's judgment must be answerable to the facts (see e.g. Newstead [2006, 193]). This criticism would stick if practical knowledge were belief-involving, for it is indeed hard to see how a belief which mismatches with the facts it aims to capture could be anything other than mistaken, and hard too, to see how someone's action could possibly be answerable to how she believes she is acting.

But if the psychological attitudes (judgments) involved in practical knowledge are not beliefs, but intentions, this objection is misplaced, and it is easy to see how practical knowledge could display Theophrastus' Feature. The trick is to understand Anscombe as using the expression 'judgment' neutrally between 'intention' and 'belief' - the 'judgment' involved in speculative knowledge is belief; the 'judgment' involved in practical knowledge is intention. (It is notable, on my interpretation, that Anscombe never uses the expression 'belief' to pick out the judgments relevant to practical knowledge.)

I have been arguing that seeing practical knowledge as involving intention analogously to how speculative knowledge involves belief best explains why practical knowledge would unlike speculative knowledge - display Aquinas' and Theophrastus' Features. But isn't there still a worry here?

For we might accept that practical knowledge would display Theophrastus' and Aquinas' Features if it involved intention rather than belief, but fail to understand how a kind of knowledge could possibly involve intention rather than belief. For as I noted in my introduction, philosophical orthodoxy has it that knowing always and per se involves believing, and so cannot - instead - involve intending. From the perspective of the Belief Account of knowledge, Anscombe's account of practical knowledge is a non-starter.

\footnotetext{
${ }^{12}$ The standard way of putting this point is in terms of the metaphor of intention and belief having different 'directions of fit'. I find this metaphor does more harm than good, and thus avoid it. Reasons for avoiding it have been given by e.g. Teichmann $(2008,23)$ Alvarez $(2010,70)$, Frost (2014).
} 
The Belief Account is the orthodox general account of knowledge, but it is not the only plausible general account of knowledge. In the next section I will outline an alternative Ability Account of knowledge and, using this as a starting-point, develop a framework within which we can make sense of the idea that knowledge might come in an intention-involving (practical) as well as a belief-involving (speculative) form.

\section{An epistemology for practical knowledge}

I start in $\$ 2.1$ by outlining and briefly motivating Hyman's Ability Account of knowledge. I then explain how to locate Anscombe's distinction between practical and speculative knowledge within the Ability Account. Doing so requires understanding the 'involvement' of a mental state in a piece of knowledge, something I have so far deliberately left intuitive, and I do this in $\S 2.2$ in terms of the relationship between an ability and a state which underwrites or grounds it. In $\S 2.3$, I then give two reasons to think that speculative knowledge is underwritten by belief, and argue by analogy that it is plausible to think of practical knowledge as underwritten by intention.

The result is a two-tier epistemology, in which the ability to use a fact as a reason is a genus, whose species are differentiated in terms of the type of mental state which underwrites this ability: the knowledge-ability is underwritten in speculative knowledge by belief, and in practical knowledge by intention.

\section{a. Introducing the Ability Account}

It is becoming relatively common to take the failure (or the lack of obvious success) of the project of defining knowledge in terms of true belief meeting some further epistemic condition to show that the concept of knowledge is unanalysable (e.g. Williamson [2000, 4]). John Hyman draws a different conclusion, that we should move away from thinking of knowledge as a kind of state - as a species of belief - and towards thinking of it as a kind of ability (Hyman 2006, 901).

Defining abilities involves describing how they are expressed, and as Hyman points out, it is relatively easy to describe how knowledge gets expressed: we express our knowledge when we use the facts we know as reasons. More precisely,

\footnotetext{
$A$ knows that $p$ if and only if the fact that $p$ can be $A$ 's reason for doing, believing, wanting or doubting something. (Hyman 1999: 442) ${ }^{13}$
}

\footnotetext{
${ }^{13}$ Hyman gives a few different glosses on the relevant ability (see e.g. 1999, 441; 2006, 901; 2015, 162), but the one above is useful because it tells us not only what knowing is, but crucially, what knowing that p is (Hyman
} 
The list, 'doing, believing, wanting or doubting' is suggestive rather than exhaustive:

[a]ny verb can be added [to 'doing', 'believing' etc.] which can occur in a sentence of the form ' $A$ 's reason for $\varphi$-ing was that $p$. (Hyman 1999: 441)

My knowing that the pangolin is endangered, for instance, is my being able to use the fact that the pangolin is endangered as a reason for doing anything which can be done for reasons; for donating money to the WWF, for believing I will find 'pangolin' on a list of endangered species, for doubting I will ever see one in the wild - but also for feeling sad, for hoping the authorities clamp down on poaching, for telling you not to eat pangolin meat, and so on. Call this the Ability Account of knowledge.

It would distract from my line of thought to fully defend the Ability Account in detail, but it is nonetheless useful to outline one central motivation for adopting it, which is independent of its capacity to make sense of practical knowledge. This concerns how well the account deals with Gettier cases. ${ }^{14}$ Consider the following, borrowed by Hyman $(1999,447)$ from Jonathan Dancy $(1985,25)$ :

\section{$\underline{\text { Re-run }}$}

Henry is watching the television on a June afternoon. It is Wimbledon men's finals day, and the television shows McEnroe beating Connors; the score is two sets to love and match point to McEnroe in the third. McEnroe wins the point. Henry believes justifiably that

1) I have just seen McEnroe win this year's Wimbledon final

and reasonably infers that

2) McEnroe is this year's Wimbledon champion.

Actually, however, the cameras at Wimbledon have ceased to function, and the television is showing a recording of last year's match. But while it does so McEnroe is in the process of

1999, 439, 442).

${ }^{14}$ It has been argued that whilst the Ability Account does well in relation to standard Gettier cases, it does not get the correct results in 'environmental luck' or 'fake barn' type cases (Hughes 2014; McGlynn 2014, 62; Locke 2015). I do not find the arguments for this conclusion convincing but it would distract from my discussion to explain why here, since my aim is to consider whether the Ability Account can help us understand practical knowledge, on Anscombe's view of it, not whether the Ability Account is independently problem-free. For some additional objections to the Ability Account, and Hyman's own responses, see his $(2015,171-184)$. 
repeating last year's slaughter. So Henry's belief (2) is true, and surely he is justified in believing (2). But we would hardly allow that Henry knows (2).

Hyman asks us to imagine, further, that 'Henry, recalling that his brother backed McEnroe and stood to win $£ 100$, infers that his brother has won $£ 100$ ' (ibid., 447). If knowing that $p$ is being able to use the fact that $p$ as a reason, then Henry, who ex hypothesi does not know that McEnroe is this year's Wimbledon champion, should not be able to use this fact as a reason for believing (inferring) that his brother has won $£ 100$.

And indeed, it does seem wrong to say that the fact that McEnroe is this year's champion is Henry's reason for believing that his brother has won $£ 100$. Henry did not believe his brother had won $£ 100$ because McEnroe is this year's champion but because he believed that McEnroe is this year's champion. This is so even though it is a fact that McEnroe is this year's champion. We can test our intuitions by considering what Henry would say if he found out that he'd been Gettiered: whilst it would seem fine for him to say 'I thought my brother had won $£ 100$ because I thought (or believed) that McEnroe was this year's champion’, it doesn’t seem right for him to say 'I thought my brother had won $£ 100$ because McEnroe is this year's champion' (Hyman 1999, 448; 2006, 905).

Its ability to deal so well with Gettier-type cases gives us some independent reason for accepting Hyman's Ability Account. And whilst the Belief Account doesn't stand a chance of accommodating Anscombe's distinction between practical and speculative knowledge (understood as in $§ 1$ ), the Ability Account does. Let's turn to seeing how.

\section{b. Knowing as 'involving' a mental state: ability and ground}

I said in $\S 1$ that we should see Anscombe's distinction between speculative and practical knowledge as a distinction between knowledge which involves belief, and knowledge which involves intention. Let's consider how to understand the relevant sense of 'involvement', starting with the case of speculative knowledge.

I know that the pangolin is endangered. What is the relationship between this knowledge and my belief that the pangolin is endangered? In some sense, we have already said, my knowledge seems to 'involve' my belief that the pangolin is endangered, but in what sense?

On Hyman's view, my knowledge is my ability to use the fact that the pangolin is endangered as a reason - as a reason for feeling sad, for telling you not to eat pangolin meat, and so on. Now, when we can talk of an ability, we can often also talk of what grounds or underwrites that ability. A bird's ability to fly, for example, is (at least partly) underwritten by, or grounded in, her physiological constitution: it is (in part) in virtue of her physiological constitution that she can fly. My ability to speak basic French is (partly) underwritten by, or 
grounded in, my understanding of certain French terms and expressions: it is (in part) in virtue of my understanding of these terms and expressions that I can speak basic French.

The idea of an ability's being underwritten or grounded is familiar from commonsense, and I think it can provide a useful way of understanding how my knowledge that the pangolin is endangered - understood as an ability - involves my belief that it is. The idea is that the relationship between the ability that is my knowledge that the pangolin is endangered, and the state that is my (true) belief that the pangolin is endangered, is just an instance of this relationship between an ability and what underwrites or grounds it. My ability to use the fact that the pangolin is endangered as a reason is (at least partially) underwritten by, or grounded in, my belief that it is endangered: it is (in part) in virtue of the fact that I believe that it is endangered that I know that it is (I will elaborate on this idea in $§ 2.3$ ).

Clearly, for this idea to work, more needs to be said about the commonsense distinction and relationship between an ability and what underwrites or grounds it. There is not room to do this in any detail here, but I do want to make a few comments about this project before moving on.

First, the idea that (speculative) knowledge that $p$ is grounded in or underwritten by a belief that $p$ is supposed to be compatible with a non-reductionist or knowledge-first epistemological approach. ${ }^{15}$ That is, it is supposed to be compatible with there being no specification of the conditions in which a belief in a fact will underwrite the ability to use that fact as a reason, which is both universal (captures all cases) and non-circular (can be stated without using the concepts of knowledge or ability to use a fact as a reason). This constrains how we should understand the ability/ground relationship.

Second, I take it that I am allowed to exploit the idea that abilities can have what I am calling 'grounds' without delving into the detailed metaphysics of grounding. ${ }^{16}$ 'The' grounding relationship which has attracted so much attention in recent years - I'll call it 'ontological grounding' - is ordinarily thought of as having features which what I am referring to as 'what grounds (or underwrites) an ability' does not.

Most obvious, perhaps - and related to the constraint described above - is the idea that if $A$ ontologically grounds $B$, then $A$ is often thought of as more ontologically fundamental than $B$ (see e.g. Bliss and Trogdon [2014, esp. §6.2]). ${ }^{17}$ Thinking of my belief that the pangolin is endangered as the ontological ground of my knowledge that it is endangered would plausibly

\footnotetext{
${ }^{15}$ Thanks to Maria Alvarez for pressing me to consider this issue more than I had done previously. It is not considered here in nearly enough depth, for reasons of space.

${ }^{16}$ A related area of literature - concerning the relationships between dispositions, capacities and categorical bases - is more likely to be of relevance to the project of fully elucidating the relationship between a piece of knowledge and the mental state which underwrites it. Again, pursuing this project must be left for another occasion.

${ }^{17}$ Thanks to Lukas Skiba for helping me think about grounding in what I am calling the 'ontological' sense.
} 
be in tension with a knowledge-first (speculative) epistemology, according to which belief is to be understood in terms of (speculative) knowledge and not vice-versa. And I at least want my account to leave room for such an approach.

Is it ad hoc to help myself to a notion of what grounds or underwrites an ability which looks so different to the notion of an ontological ground? No, for there does seem to be $a$ commonsense distinction between ability and ground which lacks the entailment to relative ontological fundamentality. It doesn't seem plausible to me that (e.g.) my understanding of certain French terms and expressions is more ontologically fundamental than my ability to speak basic French. It's hard to understand exactly what such a claim would amount to, and it would be methodologically askew to insist that my understanding of those terms and expressions must be more fundamental than my ability because we are apt to see the latter as grounded in or underwritten by the former. The philosophy of ontological grounding is a highly theoretical pursuit, so we can't assume that whenever we use the word 'ground' in natural language, we're expressing the same concept with which those interested in what I have been calling 'ontological grounding' are concerned.

Second, it has been argued that we may need more than one notion of ontological grounding (Wilson 2014; Koslicki 2015), in which case it might turn out that one emerges which fits with the commonsense notion I have roughly outlined. If it does, we will be able to apply it to the knowledge case. If not, then what the ontological grounders are interested in will turn out to be distinct from the commonsense relation I am interested in, despite their sharing a label. And this is something I have just suggested isn't a problem for the project I am outlining.

Either way, although there is more work to be done in elucidating the ability/ground relationship I have in mind, I don't see any reason to think this can't be done in a way that meets the constraints I have outlined in this section. For now, I will carry on using the word 'ground' to refer to what underwrites an ability.

\section{c. Why belief grounds speculative knowledge, and intention grounds practical knowledge}

This section outlines two considerations which make it plausible to think that my ability to use the fact that the pangolin is endangered as a reason, is underwritten by my belief that the pangolin is endangered, and argues that parallel considerations support the conclusion that my ability to use the fact that I am intentionally $\varphi$-ing as a reason is plausibly underwritten by my intention to $\varphi$.

The first consideration is that when I express my knowledge that the pangolin is endangered, I seem to do so by expressing my belief that it is. Say you ask why I am feeling sad, and I say 'Because the pangolin is endangered' (something I've only just found out, 
perhaps). Stipulate that I am herein expressing knowledge. In expressing this knowledge I represent myself as able to use the fact that the pangolin is endangered as a reason (because I suggest that I have used it as a reason - for feeling sad). Why also think I am doing so by expressing my belief?

One reason is that my assertion, ' $\ldots$ the pangolin is endangered' seems to be subject to kinds interrogation which are appropriate to expressions of belief but not to expressions of knowledge. You can ask me 'Why do you think/what's your reason for thinking that?', or, 'Are you sure?', or 'How sure are you?' We don't ask questions like this in response to assertions qua expressions of knowledge. ${ }^{18}$ It is not appropriate to ask someone qua $p$-knower how sure they are that $p$. And whilst we might ask someone, 'How do you know that?', this is a different question to 'Why do you think that?' A 'How?' question asks for an explanatory reason, a 'Why?' question for a normative reason: the questions have different senses. We ask for normative reasons for believing but not for knowing. If my assertion ' ... the pangolin is endangered' can be interrogated in the ways appropriate to belief but not appropriate to knowledge (as well as being able to be interrogated in the ways appropriate to knowledge, of course), this suggests that it expresses belief as well as knowledge. This is one reason why it seems plausible to think of my knowledge that the pangolin is endangered as involving my belief that it is.

Consider now a bit of knowledge of intentional action - my knowledge that I am (intentionally) going to the bar, say. Parallel considerations motivate thinking of this knowledge as involving my intention to go to the bar. Say Alexander asks why I am checking my wallet, and I respond, 'Because I am going to the bar'. Stipulate that in so doing I express knowledge.

In expressing this knowledge, I represent myself as able to use the fact that I am going to the bar as a reason (because I represent myself as having used it as a reason - for checking my wallet). But here I seem to express my knowledge by expressing, not a belief that I am going to the bar, but my intention to go to there.

This requires a little explanation and defence, for which we can initially turn back to Anscombe.

Anscombe describes an important truism about the way in which expressions of intention differ from expressions of belief:

[A]n expression of intention is a description of something future in which the speaker is some sort of agent, which description he justifies (if he does justify it) by reasons for acting, sc. reasons why it would be useful or attractive if the description came true, not by evidence that it is true. (6)

\footnotetext{
${ }^{18}$ For some related comments see Austin (1946, 149-50).
} 
This truism gives us a test for when a 'description of something future in which the speaker is some sort of agent' expresses an intention. And, applying the test, it seems that I would justify my statement ' ... I am going to the bar' in this way, if confronted with 'Why?', saying, perhaps, 'I want another drink and I owe Alexander one too.' Saying this doesn't give a reason for believing I will go to the bar, but a reason for going there, suggesting that I express my knowledge that I am going to the bar by expressing my intention to go there, not by expressing a belief that I am going there.

The second commonsense consideration which seems to underwrite the intuition that my knowledge that the pangolin is endangered involves my belief that it is, stems from thinking about cases where a person fails to know. As is often observed, and as Hyman highlights, 'I believed that $p$ ' is what a person retreats to after accepting that she did not know that $p$ (Hyman 1999, 445). Were I provided with new - and persuasive - evidence against thinking that the pangolin is endangered, I might respond by saying 'Oh. Well I thought (believed) it was endangered - all the evidence seemed to point to that. I guess I was missing some crucial information'.

Timothy Williamson suggests that a case in which a person's attempt at knowledge fails, is a case in which '[their] mind is maladapted to [the] world', resulting in 'a residue of belief' (2000, 1; see also Williamson, forthcoming). On the view I am pressing, on which practical knowledge involves intention analogously to how speculative knowledge involves belief, this is only half-right: a residue of belief will be left when a person fails of speculative knowledge, but when a person fails to know what she is intentionally doing - when she fails of practical knowledge - the residue left over will not be belief but intention.

If I am right about this, then we should expect a person who fails to know what she is intentionally doing not to retreat to a claim about what she believed she was doing, but to a claim about what she intended. And indeed this is just what we find. Imagine that on my way to the bar, I bump into Ellisif, my housemate, who is off home. We get chatting and I end up, absent-minded as I am, walking home with her. Alexander calls up: 'Where are you? - You said you were going to go to the bar but you've disappeared!' I can't sensibly retreat to 'Oh. Well I thought (believed) I was going to the bar. All the evidence seemed to point to that - I guess I was missing some crucial information'. Instead I will retreat to something like 'Sorry, I meant to (intended to) go there - I was going to buy you a drink... I just, sort of, forgot.' Hardly a good excuse, but true nonetheless.

To sum up, it is plausible to say that speculative knowledge is underwritten by belief, because first, we seem to express speculative knowledge by expressing beliefs, and second, failures of speculative knowledge leave a 'residue' of belief. Analogous considerations, applied 
to our knowledge of our intentional actions, suggests that this knowledge is underwritten not by belief but by intention.

The picture which results from merging Anscombe's and Hyman's epistemologies is a two-tier account of knowledge as a genus containing two species. Hyman's Ability Account of knowledge gives us the genus, and Anscombe's distinction between practical and speculative knowledge (understood as an intention-involving and a belief-involving kind of knowledge) gives us the species. I have fleshed this idea out by exploiting a general distinction between an ability and what grounds it, and by showing that it is plausible that whereas in speculative knowledge, the knowledge-ability is grounded in belief, in practical knowledge it is grounded in intention.

\section{Conclusion}

The picture I have given is incomplete in various respects. A fuller defence and development would require, in particular, getting clearer on the specifics of the relationship between the knowledge-ability and the mental state which underwrites or grounds it. But the two-tier account I have sketched is nevertheless promising. By way of concluding, I will clarify how Anscombe's and Hyman's epistemologies mutually benefit from being associated with one another in the way I have suggested, and explain how my two-tier framework might also help us to understand a further kind of knowledge, psychological self-knowledge, which seems neither 'practical' nor 'speculative' in Anscombe's senses.

First, the benefits to the Anscombean. One reason Anscombe's account of practical knowledge has been so controversial is, I think, that there is a prima facie tension between, on the one hand, asserting that practical knowledge is radically formally distinct from speculative knowledge and, on the other, insisting that it is just like speculative knowledge in being precisely that - knowledge. How could two phenomena have different formal relationships with their objects (Aquinas' Feature), different success conditions (Theophrastus' feature), involve different psychological attitudes (belief and intention), and yet both equally belong to the same genus?

Understanding Anscombe's distinction in the context of the Ability Account provides an answer to this question: having practical and having speculative knowledge are both equally having the ability to use a fact as a reason - it's just that this ability can be grounded in very different ways. (The idea that an ability can be differentially grounded needn't alarm us: consider how differently a dog's ability to swim is grounded compared to a snake's ability to swim.)

Now the benefits to the Hymanian. By simply identifying knowledge with the ability to use a fact as a reason, Hyman glosses over important differences within the category of 
knowledge, some of which we considered in $\S 1.2$ when we saw that commonsense represents practical knowledge as differing from ordinary empirical knowledge of other worldly facts in being first-person authoritative and epistemically ungrounded. ${ }^{19}$ What explains these differences?

On Hyman's view considered on its own, nothing does. But as we also saw in $\S 1.2$, thinking of practical knowledge as involving intention analogously to how speculative knowledge involves belief explains them very neatly, by explaining why practical knowledge should display Aquinas' and Theophrastus' Features. Associating the Ability Account with Anscombe's epistemology enables an Ability Theorist to simply take over these explanations, and so to make discriminations within the category of knowledge which seem to be demanded by our commonsense concepts.

The second benefit of my two-tier account involves considering a kind of knowledge which has not been at issue in this paper. For practical knowledge is not the only kind of knowledge which seems to display different clusters of features to those we find in ordinary speculative knowledge. Psychological self-knowledge - our knowledge of our own current mental states - is, like practical knowledge, commonly thought of as first-person authoritative and epistemically ungrounded. And plausibly has different features to practical knowledge, too. For example, whilst I might intelligibly think I am intentionally kicking Rory, when I am in fact kicking Jen (although of course not intentionally), I do not seem able to intelligibly think that I believe that Jeremy Corbyn is Prime Minister whereas I in fact believe that Theresa May is, or to intelligibly mistake a headache for a stomach-ache. That is, there are certain possibilities of rational failure of practical knowledge which simply don't exist when it comes to psychological self-knowledge.

Hyman has pointed out that his Ability Account can easily accommodate psychological self-knowledge $(1999,450-451 ; 2015,185-188)$ : a person can surely use the fact that she has a headache, or believes that Theresa May is Prime Minister, or wants another drink, or is worried about tomorrow's hangover, as a reason. Perhaps the peculiar set of features which characterise psychological self-knowledge can, too, be understood as stemming from the nature of the mental state that grounds such knowledge, where as with practical knowledge, this is not a belief in the fact that one knows.

Which mental states might ground the abilities to use facts about our own mental states as reasons? Plausibly, these very states themselves. The suggestion to be considered is that my ability to use the fact that I have a headache as a reason is grounded in my headache, my ability to use the fact that I want another drink as a reason is grounded in my desire for another drink;

${ }^{19}$ I do not claim that Hyman wants to explain these differences - only that he does not in fact do so. 
my ability to use the fact that I am worried about tomorrow's hangover as a reason is grounded in my worry about tomorrow's hangover, and so on.

The idea - only suggestive, but worth exploring - is that practical knowledge is not the only kind of knowledge which might be better understood by a reorientation away from the orthodox epistemology I have been calling the Belief Account, and towards the two-tier epistemology I have introduced in this paper.

\section{References}

Alvarez, Maria. 2010. Kinds of Reasons: An Essay in the Philosophy of Action. Oxford: Oxford University Press.

Anscombe, G. E. M. 1957. Intention. Cambridge, MA: Harvard University Press.

Anscombe, G. E. M. 1979. “Under a Description.” Noûs 13 (2): 219-233.

Austin, J. L. 1946. "Other Minds." Proceedings of the Aristotelian Society Supplementary Vol. 20: 14887.

Bliss, Ricki, and Kelly Trogdon. 2014. "Metaphysical Grounding.” Stanford Encyclopedia of Philosophy. http://plato.stanford.edu/entries/grounding/.

Bratman, Michael. 1984. "Two Faces of Intention.” Philosophical Review 93 (3): 375-405.

Bratman, Michael. 2009. "Intention, Belief, Practical, Theoretical." In Spheres of Reason: New Essays in the Philosophy of Normativity, edited by Simon Robertson, 29-61. Oxford: Oxford University Press.

Dancy, Jonathan. 1985. Introduction to Contemporary Epistemology. Oxford: Blackwell.

Davidson, Donald. 2001. “Agency.” In Essays on Actions and Events. Oxford: Clarendon Press.

Donnellan, Keith S. 1963. "Knowing What I Am Doing." Journal of Philosophy 60 (14): 401-409.

Ezio, di Nucci. 2009. "Simply, False.” Analysis 69 (1): 69-78.

Frost, Kim. 2014. "On the Very Idea of Direction of Fit." Philosophical Review 123 (4): 429-84.

Grünbaum, Thor. 2009. "Anscombe and Practical Knowledge of What Is Happening.” Grazer Philosophische Studien 78: 41-67.

Haddock, Adrian. 2011. "The Knowledge that a Man has of his Intentional Actions." In Essays on Anscombe's Intention, edited by Anton Ford, Jennifer Hornsby, and Frederick Stoutland, 147-69. Cambridge, MA: Harvard University Press.

Holton, Richard. 2009. Willing, Wanting, Waiting. Oxford: Oxford University Press.

Hughes, Nick. 2014. "Is Knowledge the Ability to $\varphi$ for the reason that P?" Episteme 11 (4): 457-62.

Hyman, John. 1999. “How Knowledge Works.” The Philosophical Quarterly 49 (197): 433-51.

Hyman, John. 2006. “Knowledge and Evidence.” Mind 115 (460): 891-916.

Hyman, John. 2015. Action, Knowledge and Will. Oxford: Oxford University Press. 
Koslicki, Kathrin. 2015. "The Coarse-Grainedness of Grounding.” In Oxford Studies in Metaphysics, edited by Karen Bennett and Dean Zimmerman, 9:306-41. Oxford Studies in Philosophy. Oxford: Oxford University Press.

Langton, Rae. 2004. "Intention as Faith.” In Agency and Action. Cambridge: Cambridge University Press.

Locke, Dustin. 2015. “Knowledge, Explanation, and Motivating Reasons.” American Philosophical Quarterly 52 (3): 215-32.

McGlynn, Aidan. 2014. Knowledge First? Basingstoke: Palgrave Macmillan.

Moran, Richard. 2004. “Anscombe on 'Practical Knowledge."” In Agency and Action (Royal Institute of Philosophy Suppl. 55), 55:43-68. Cambridge: Cambridge University Press.

Newstead, Anne. 2006. “Knowledge by Intention? On the Possibility of Agent's Knowledge.” In Aspects of Knowing: Epistemological Essays, edited by Stephen Hetherington, 183-202. Perspectives on Cognitive Science. Oxford: Elsevier.

Newstead, Anne. 2009. “Interpreting Anscombe’s Intention §32FF.” Journal of Philosophical Research 34: $157-176$.

O’Brien, Lucy. 2003. “On Knowing One’s Own Actions.” In Agency and Self-Awareness, 358-82. Oxford: Clarendon Press.

Paul, Sarah K. 2009. "How We Know What We're Doing.” Philosophers' Imprint 9 (11): 1-24.

Pickard, Hanna. 2004. "Knowledge of Action Without Observation." Proceedings of the Aristotelian Society 104 (3): 203-28.

Rödl, Sebastian. 2007. Self-Consciousness. Cambridge, MA: Harvard University Press.

Setiya, Kieran. 2008. "Practical Knowledge.” Ethics 118 (3): 388-409.

Setiya, Kieran. 2009. "Practical Knowledge Revisited.” Ethics 120 (1): 128-137.

Teichmann, Roger. 2008. The Philosophy of Elizabeth Anscombe. Oxford: Oxford University Press.

Thompson, Michael. 2011. “Anscombe's Intention and Practical Knowledge.” In Essays on Anscombe’s Intention. Harvard University Press.

Velleman, David. 1989. Practical Reflection. Princeton, NJ: Princeton University Press. 2000. The Possibility of Practical Reason. Oxford: Oxford University Press.

Williamson, Timothy. Forthcoming. “Acting on Knowledge.” In Knowledge-First, edited by J. A. Carter, E. Gordon, and B. Jarvis. Oxford: Oxford University Press.

Williamson, Timothy. 2000. Knowledge and Its Limits. Oxford: Oxford University Press.

Wilson, J. 2014. "No Work for a Theory of Grounding." Inquiry 57 (5-6): 1-45.

Wiseman, Rachael. 2016. Routledge Philosophy Guidebook to Anscombe’s Intention. Routledge Philosophy Guidebooks. Abingdon: Routledge. 